\title{
NLTE Model Atmospheres with Rotation
}

\author{
Daniela Korčáková ${ }^{1,2}$ and Jiří Kubát ${ }^{1}$

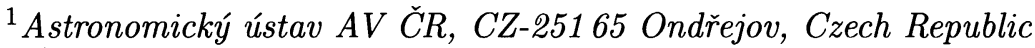 \\ ${ }^{2}$ Ústav teoretické fyziky a astrofyziky PřF MU, Kotlářská 2, CZ-611 37 \\ Brno, Czech Republic
}

\begin{abstract}
We present a modification of our code for calculation of NLTE model atmospheres in planar and spherical geometry to the case of rotating atmospheres. This modification enables self-consistent inclusion of the effect of rotation on the atmospheric structure.
\end{abstract}

\section{Introduction}

Plane parallel approximation is being commonly used for the analysis of stellar atmospheres. This approximation is good for the analysis of thin atmospheres where the thickness of the atmosphere is much smaller than the stellar radius. The rotationally broadened line profile is usually calculated simply as a convolution of the line profile and of the rotation profile (cf. Gray 1976).

This situation changes if the thickness of the atmosphere is not negligible with respect to the stellar radius. There are several effects that change the resulting line profiles. Analytical expressions for limb darkening do not give a correct description of the angular dependence of the specific intensity. They also do not take into account the fact that the limb darkening is strongly dependent upon frequency across the line profile (cf. Hadrava \& Kubát 2003). In order to describe the radiation field and its influence on the stellar atmosphere correctly, it is necessary to take into account the Doppler shift of lines in rotating atmospheres for transfer of radiation along nonradial rays. This problem may be solved only using more spatial dimensions for the description of the radiation field. Here we describe a method for the solution of the radiative transfer equation in axial symmetry, which is the natural approximation for the description of the stellar rotation (cf. Korčáková \& Kubát 2003b).

\section{Formal Solution of the Radiative Transfer Equation}

The most important part of the model atmosphere calculation is the formal solution of the radiative transfer equation. The simplest approximation is the plane parallel one. Slightly more general, but still one-dimensional is the spherically symmetric approximation, as has been used in an older version of our NLTE model atmosphere code (Kubát 2003a, 2003b).

A more general solution is the two dimensional solution in axial symmetry, which allows for a description of pole-to-equator changes of stellar surface parameters. A brief description of this method can be found in Korčáková \& 


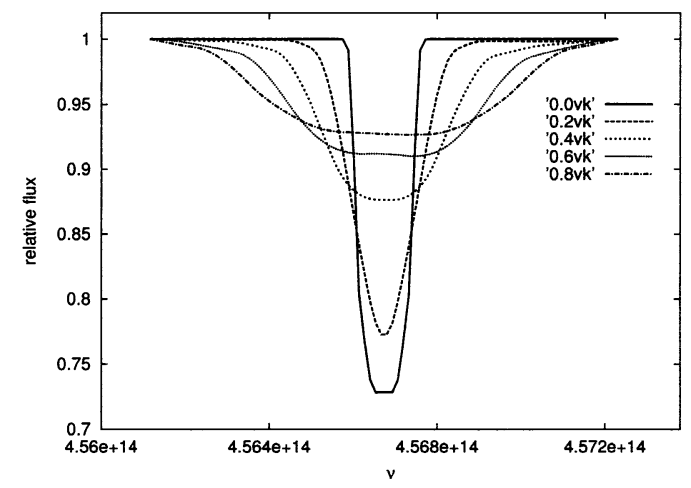

Figure 1. The $\mathrm{H} \alpha$ line profile for different rotational velocities as a fraction of the critical velocity ( $\mathrm{vk}=540 \mathrm{~km} \mathrm{~s}^{-1}$ ) for a rotating atmosphere calculated using the two-dimensional radiative transfer code.

Kubát (2003b). Generalization of this method to moving media is performed including the Doppler shift as described in Korčáková \& Kubát (2003a).

\section{Results of Line Profile Calculations}

As a test example we calculated $\mathrm{H} \alpha$ line profiles of a rotating atmosphere for different rotational velocities using the 2D axially symmetric code (see Figure 1). The static spherically symmetric NLTE hydrogen-helium model atmosphere was calculated for $T_{\text {eff }}=17200 \mathrm{~K}, \log g=4.12$ (Kubát 2003b). The rotated line profiles have the so-called U-shape, as expected. Current results show that the radiative transfer axially symmetric code works correctly and it may be applied to consistent NLTE model calculations of rotating stellar atmospheres and disks.

Acknowledgments. This work was supported by grants 205/02/0445 and 205/01/0656 (GA ČR), and by projects K2043105 and AV 0Z1 003909.

\section{References}

Gray, D. F. 1976, Observation and Analysis of Stellar Photospheres, John Wiley \& Sons, New York

Hadrava, P., Kubát, J. 2003, in Stellar Atmosphere Modelling, I. Hubeny, D. Mihalas \& K. Werner eds., ASP Conf. Ser., in press

Korčáková, D., Kubát, J. 2003a, A\&A, submitted

Korčáková, D., Kubát, J. 2003b, in Modelling of Stellar Atmospheres, IAU Symp. 210, N. E. Piskunov, W. W. Weiss \& D. F. Gray eds., ASP Conf. Ser., submitted

Kubát J. 2003a, in Stellar Atmosphere Modelling, I. Hubeny, D. Mihalas \& K. Werner eds., ASP Conf. Ser., in press

Kubát J. 2003b, in Modelling of Stellar Atmospheres, IAU Symp. 210, N. E. Piskunov, W. W. Weiss \& D. F. Gray eds., ASP Conf. Ser., submitted 